\title{
High expression of metabolic enzyme PFKFB4 is associated with poor prognosis of operable breast cancer
}

Ling Yao ${ }^{1,2,3+}$, Lei Wang ${ }^{1,2,3 \dagger}$, Zhi-Gang Cao ${ }^{1,2,3}$, Xin Hu ${ }^{1,2,3^{*}}$ and Zhi-Ming Shao ${ }^{1,2,3,4^{*}}$

\begin{abstract}
Background: Enhanced glycolysis in tumors, known as the Warburg effect, provides the metabolic basis of enhanced cancer cell proliferation and metastasis. The Warburg pathway enzyme 6-phosphofructo-2-kinase/fructose2,6-bisphosphatase 4 (PFKFB4) is a newly identified key kinase that regulates transcriptional reprogramming and cell proliferation. Here we show the prognostic value of PFKFB4 expression in patients with operable breast cancer.

Methods: PFKFB4 expression was evaluated by immunohistochemistry in surgical specimens retrospectively collected from 200 patients with histologically proven invasive ductal breast cancer. Kaplan-Meier survival analysis and Cox regression analysis were performed to assess the prognostic significance of PFKFB4 expression.

Results: Kaplan-Meier survival analysis revealed that breast cancer patients with high PFKFB4 expression demonstrated unfavorable disease-free survival $(p=0.008)$ and overall survival $(p=0.002)$. PFKFB4 had an hazard ratio (HR) of $7.38(95 \% \mathrm{Cl} 1.69-32.3 ; p=0.008)$ in univariate Cox analysis and retained prognostic power (HR 7.44, 95\% Cl 1.67-33.2; $p=0.009$ ) when adjusted by tumor size, lymph node status, grade, estrogen receptor status, human epidermal growth factor receptor 2 status and subtype, which indicated PFKFB4 was an independent prognostic factor in breast cancer.
\end{abstract}

Conclusions: Together, our findings establish the prognostic value of metabolic enzyme PFKFB4 in patients with operable breast cancer.

Keywords: PFKFB4, Overall survival, Disease-free survival, Breast cancer

\section{Background}

Breast cancer is the most common cancer in women cancer and the second highest cause of cancer-related death in women in the United States [1]. In China, breast cancer is also the most commonly diagnosed cancer and accounts for $15 \%$ of all new cancers in women [2]. Breast cancer is a heterogeneous disease composed of four subtypes: luminal A, luminal $\mathrm{B}$, human epidermal growth factor receptor 2 (HER-2)-enriched and triple-negative [3]. According to current guidelines and consensus, the

\footnotetext{
*Correspondence: xinhu.nlorg@gmail.com; shao_zhi_ming@126.com

${ }^{\dagger}$ Ling Yao and Lei Wang contributed equally to this work

1 Department of Breast Surgery, Key Laboratory of Breast Cancer in Shanghai, Fudan University Shanghai Cancer Center, Fudan University, 270 Dong-An Rd., Shanghai 200032, People's Republic of China Full list of author information is available at the end of the article
}

selection of an appropriate adjuvant therapy regimen is largely based on the subtype and risk recurrence category. The value of prognostic biomarkers and gene-based assays has recently been added into the 8th edition of the primary tumor, lymph node, and metastasis (TNM) classification of the American Joint Commission of Cancer for breast cancer [4]. Despite the intensive research into the mechanisms of breast cancer performed over the past decades, very few of the identified critical molecules have been adopted for therapeutic or prognostic approaches in clinical practice. Thus, there is an urgent need to identify novel biomarkers that provide additional risk assessment for personalized treatment.

In recent years, studies of cancer metabolism have provided insight into the process of adaptation of cancer cells, which alter their metabolic activity to meet 
the increased needs for energy and biosynthetic precursors. Enhanced glycolysis, known as the Warburg effect, is observed in many cancers and provides the metabolic basis of cancer cell proliferation [5]. The Warburg pathway enzyme 6-phosphofructo-2-kinase/fructose-2,6-bisphosphatase 4 (PFKFB4) is a newly identified key factor that regulate transcriptional reprogramming and functions as the most dominant kinase that regulates cell proliferation [6]. Several studies identified PFKFB4 as a key molecule in multiple cancers, including breast cancer [6], prostate cancer [7] and glioma [8]. However, our current knowledge about PFKFB4 has largely originated from in vitro studies, and the in vivo relevance of this molecule requires further study. Furthermore, the prognostic value of the PFKFB4 protein in breast cancer has not been investigated.

In this study, we evaluated the prognostic power of PFKFB4 expression in 200 tumor samples from patients with stage I to III breast cancer. We examined the associations between PFKFB4, clinicopathological variables and survival. Our results indicated that elevated PFKFB4 is strongly associated with shorter disease-free survival (DFS) and overall survival (OS) and indicate that PFKFB4 could serve as a novel prognostic factor in breast cancer.

\section{Materials and methods}

\section{Patients and specimens}

Clinical data and surgical specimens were retrospectively collected from 200 female patients who were diagnosed with stage I to III primary breast cancer at the Department of Breast Surgery in Fudan University Shanghai Cancer Center (FUSCC, Shanghai, China) between January 2004 and January 2008. All specimens in this cohort were histologically confirmed with invasive ductal carcinoma and all participants underwent a mastectomy and axillary lymph node dissection or breast conservation surgery. Treatment decisions, including chemotherapy, radiation therapy, target therapy or endocrine therapy, were performed at the discretion of clinicians following the Chinese Anti-Cancer Association's guidelines. All patients were regularly followed, with the last update occurring in October 2014. This study was approved by the Ethics Committee of FUSCC, and written informed consent was acquired from all patients.

Data of the clinicopathological variables and expression status of estrogen receptor (ER), progesterone receptor (PR) and human epidermal growth factor receptor 2 (HER-2) in the surgical specimens were retrospectively collected from the medical database of FUSCC. Since Ki-67 expression status was not available in all cases, we defined breast cancer subtypes as follows: luminal (ER and/or PR positive, HER-2 negative); HER-2-enriched
(ER and PR negative, HER-2 positive); and triple-negative (ER negative, PR negative, HER-2 negative).

\section{Tissue microarray preparation}

Tissue microarrays (TMAs) were constructed as previously described [9]. Briefly, breast cancer specimens from the 200 surgical cases described above were fixed using standard protocols. Archived and de-identified formalin-fixed paraffin-embedded (FFPE) samples were then analyzed. After histological examination of the tissue samples by our dedicated pathologist, TMAs were developed by punching two 10-mm-diameter cores out of each tumor at two different sites. The TMAs were prepared using a Quick-Ray tissue arrayer (Unitma Co., Ltd., Seoul, South Korea) at the Department of Pathology in FUSCC. The use of the tissue samples was approved by the Institutional Review Board at FUSCC.

\section{Immunohistochemistry staining and evaluation}

As in our previous study $[9,10]$, the TMAs were subjected to immunohistochemical staining for PFKFB4 using a two-step protocol (GTVision ${ }^{\mathrm{TM}}$ III). PFKFB4 was detected using the rabbit anti-PFKFB4 polyclonal antibody [ab137785] (1:50;Abcam). The negative controls were generated using phosphate-buffered saline instead of primary antibody. Positive controls were established according to the instructions provided with the antibodies. The PFKFB4 staining intensity was rated according to four scores ( 0 denoting negative; 1 , weak; 2 , moderate; and 3, strong). The stained TMAs were evaluated independently by two experienced pathologists who were blinded to all clinical data on a case-by-case basis. Because the TMAs represented duplicate samples for each case, the score used in all subsequent analyses was the average across the available scores. The cutoff value for high and low PFKFB4 expression was the median value of the intensity scores.

\section{Statistical analysis}

Patient clinicopathological variables were summarized for all participants using standard descriptive statistics. The Pearson $\chi^{2}$ test was performed to compare qualitative variables, and Fisher's exact test was used when necessary. DFS was defined as the time from the date of primary surgery to the date of recurrence, distant metastasis or death. OS was calculated from the date of primary surgery to the date of death. The follow-up period was defined as the time from surgery to relapse or death (for complete observations) or to the last observation (for censored cases).

Survival analysis was performed using the KaplanMeier method and log-rank test was used to test the differences in survival by covariates. Reverse Kaplan-Meier 
method was used to calculate the median follow-up time. Univariate Cox regression models were fitted to estimate the effect of clinicopathological variables and PFKFB4 at the time-to-event endpoints (DFS and OS events). Multivariate analyses were performed to estimate the risk of variables in which Wald $p$ were smaller than 0.20 in univariate analyses. All statistical analyses were performed using SPSS statistics version 24 (SPSS Inc., Chicago, IL, USA). All reported $p$ values were two-sided, and $p<0.05$ was considered statistically significant.

\section{Results}

\section{Expression pattern of PFKFB4 in breast cancer}

A total of 200 female patients with invasive ductal breast cancers were recruited in this study. The average age of the participants was 50.4 years (standard deviation 10.4, median 50.0, range 26-84). The clinicopathological characteristics of the cohort are summarized in Table 1. After a median follow-up time of 93.9 months, 37 of the 200 patients experienced recurrence or death. To investigate the clinical significance of PFKFB4 in breast cancer, we conducted immunohistochemical staining for PFKFB4 expression in the tumor samples. As shown in Fig. 1, positive staining for PFKFB4 protein was observed mainly in the cytoplasm of breast cancer cells, and most of the intra- or extra-tumor stromal cells were negative for PFKFB4. Using the semi-quantified scoring criteria, positive PFKFB4 staining was observed in 98 (49.0\%) of the 200 cases (Table 1). Higher PFKFB4 expression was associated with ER status $(p=0.021)$ and had a borderline relationship with PR status $(p=0.059)$ and subtype $(p=0.068)$.

\section{Elevated PFKFB4 expression is associated with poor DFS and $O S$ in breast cancer}

To evaluate the clinical implications of PFKFB4 overexpression in breast cancer, we assessed the correlation between PFKFB4 status and DFS and OS using KaplanMeier survival analysis. As shown in Fig. 2a, b, patients with high PFKFB4 expression showed unfavorable DFS $(p=0.008)$ and OS $(p=0.002)$. After stratification by molecular subtypes, PFKFB4 predicted poor DFS in luminal breast cancer $(p=0.018$; Fig. $2 \mathrm{c})$ and better OS was observed in TNBC patients with low PFKFB4 expression $(p=0.017$; Fig. $2 \mathrm{~h})$. However, no survival association was observed in the HER-2-enriched subgroup $(p>0.05$; Fig. 2e, f). There was no positive correlation between PFKFB4 and OS in the luminal subtype ( $p>0.05$; Fig. $2 d)$ and OS showed no significance in TNBC patients when stratified by PFKFB2 status ( $p>0.05$; Fig. $2 \mathrm{~g})$. These results suggest that the molecular function of PFKFB4 in breast cancer may depend on the molecular subtype, which is largely determined by receptor status.
Table 1 Clinicaopathological variables and the expression of PFKFB4

\begin{tabular}{|c|c|c|c|c|}
\hline \multirow[t]{2}{*}{ Variable } & \multirow{2}{*}{$\begin{array}{l}\text { Number } \\
\text { of patients }\end{array}$} & \multicolumn{2}{|c|}{ PFKFB4 expression } & \multirow[t]{2}{*}{$p$-value } \\
\hline & & $\begin{array}{l}\text { Negative } \\
\text { number } \\
(\%)\end{array}$ & $\begin{array}{l}\text { Positive } \\
\text { number } \\
(\%)\end{array}$ & \\
\hline Total & 200 & $102(51.0)$ & $98(49.0)$ & \\
\hline Age (years) & & & & 0.453 \\
\hline$\leq 50$ & 113 & $55(48.7)$ & $58(51.3)$ & \\
\hline$>50$ & 87 & $47(54.0)$ & $40(46.0)$ & \\
\hline Menopausal status & & & & 0.837 \\
\hline Premenopausal & 121 & $61(50.4)$ & $60(49.6)$ & \\
\hline Postmenopausal & 79 & $41(51.9)$ & $38(48.1)$ & \\
\hline Tumor size (cm) & & & & 0.168 \\
\hline$\leq 2$ & 95 & $50(52.6)$ & $45(47.4)$ & \\
\hline$>2, \leq 5$ & 91 & $48(52.7)$ & $43(47.3)$ & \\
\hline$>5$ & 8 & $1(12.5)$ & $7(87.5)$ & \\
\hline $\begin{array}{l}\text { Cannot be meas- } \\
\text { ured }\end{array}$ & 6 & $3(50.0)$ & $3(50.0)$ & \\
\hline Lymph node status & & & & 0.890 \\
\hline Negative & 99 & $50(50.5)$ & $49(49.5)$ & \\
\hline Positive & 101 & $52(51.5)$ & $49(48.5)$ & \\
\hline Grade & & & & 0.716 \\
\hline Grade 1 & 2 & $1(50.0)$ & $1(50.0)$ & \\
\hline Grade 2 & 94 & $52(55.3)$ & $42(44.7)$ & \\
\hline Grade 3 & 56 & $26(46.4)$ & $30(53.6)$ & \\
\hline Unknown & 48 & $23(47.9)$ & $25(52.1)$ & \\
\hline ER status & & & & 0.021 \\
\hline Negative & 112 & $49(43.8)$ & $63(56.3)$ & \\
\hline Positive & 88 & $53(60.2)$ & $35(39.8)$ & \\
\hline PR status & & & & 0.059 \\
\hline Negative & 113 & $51(45.1)$ & $62(54.9)$ & \\
\hline Positive & 87 & $51(58.6)$ & $36(41.4)$ & \\
\hline HER2 status & & & & 0.120 \\
\hline Negative & 99 & $45(45.5)$ & $54(54.5)$ & \\
\hline Positive & 101 & $57(56.4)$ & $44(43.6)$ & \\
\hline Subtype ${ }^{b}$ & & & & 0.068 \\
\hline Luminal & 100 & $58(58.0)$ & $42(42.0)$ & \\
\hline HER2-enriched & 50 & $25(50.0)$ & $25(50.0)$ & \\
\hline Triple-negative & 50 & $19(38.0)$ & $31(62.0)$ & \\
\hline
\end{tabular}

ER estrogen receptor, HER-2 human epidermal growth factor receptor 2, PFKFB4 6-phosphofructo-2-kinase/fructose-2,6-bisphosphatase 4, $P R$ progesterone receptor

a Based on the Pearson $X^{2}$ test (Fisher's exact test was used when needed)

${ }^{b}$ Definitions of subtypes: luminal (ER- and/or PR-positive), HER-2-enriched (ERand PR-negative, HER-2-positive), and triple-negative (ER-negative, PR-negative, and HER-2-negative)

Moreover, since PFKFB4 can regulate ER [6], we further investigated the survival relationship of PFKFB4 in breast cancer patients stratified by ER status. High PFKFB4 was associated with poor DFS in ER-positive patients $(p=0.020$; Additional file 1: Figure $\mathrm{S} 1 \mathrm{~A})$, whereas low 


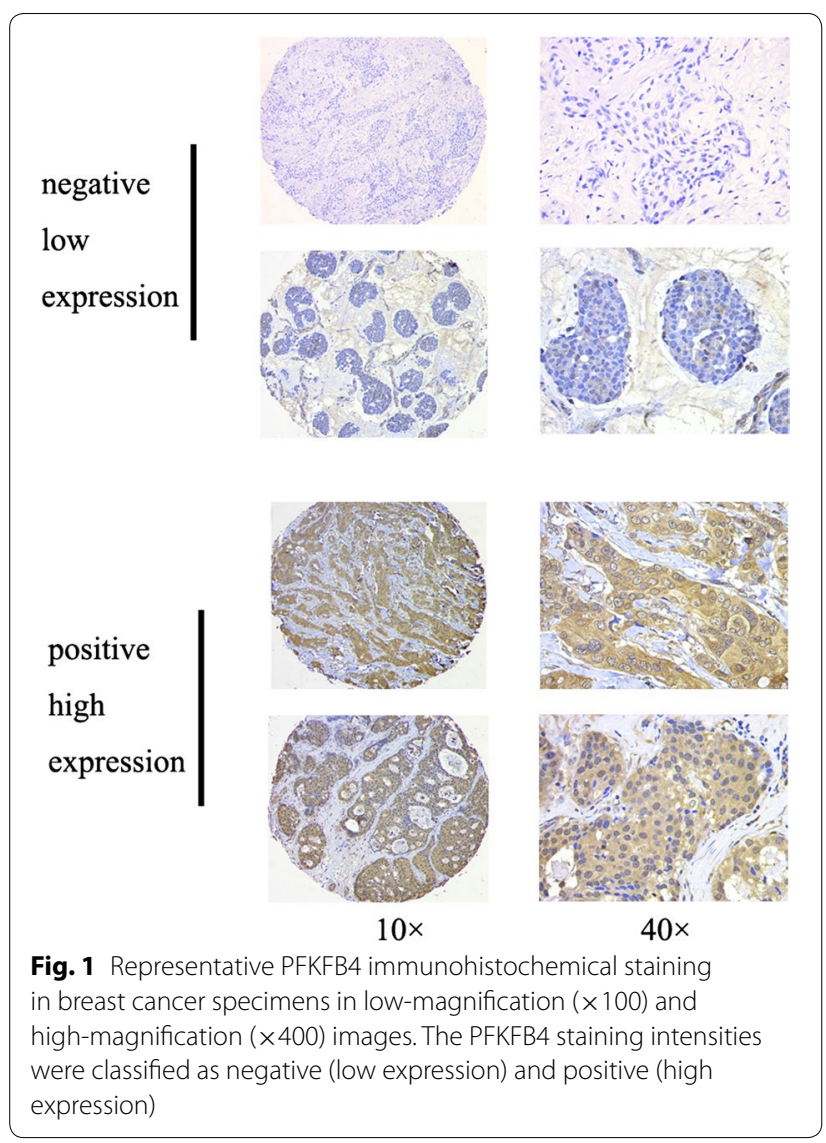

expression of PFKFB4 predicted favorable long-term outcome in ER-negative patients ( $p=0.004$; Additional file 1: Figure S1D). No positive correlation between PFKFB4 expression and OS was observed ( $p>0.05$; Additional file 1: Figure S1B), and comparison of DFS in ER-negative subgroups revealed no significant difference when stratified by PFKFB4 status $(p>0.05$; Additional file 1: Figure $\mathrm{S} 1 \mathrm{C})$.

\section{Univariate and multivariate Cox regression analyses}

Next, we examined the correlation between DFS and the clinicopathological variables in the univariate Cox analyses. As shown in Table 2, PFKFB4 (HR 2.52, 95\% CI 1.24-5.11; $p=0.010$ ) and triple-negative subtype (HR $2.19,95 \%$ CI $1.10-4.35 ; p=0.025)$ were associated with a higher risk of relapse and death. After adjustment by variables for which HR were smaller than 0.2, PFKFB4 remained a significant prognostic factor with an HR of 2.42 (95\% CI 1.17-5.00; $p=0.017$ ).

Table 3 presents the association between OS and the clinicopathological variables analyzed using univariate and multivariate Cox regression. PFKFB4 had an HR of 7.38 (95\% CI 1.69-32.3; $p=0.008$ ) and retained prognostic power (HR 7.44, 95\% CI 1.67-33.2; $p=0.009$ ) when adjusted by tumor size, lymph node status, grade, ER status, HER2 status and subtypes. Lymph node status, a traditional prognostic factor, was associated with poor OS as well (HR 3.41, 95\% CI 1.08-10.8; $p=0.037$ ). Thus, PFKFB4 was established to be an independent prognostic factor in breast cancer.

\section{Discussion}

Increasing recognition of the active role of cancer metabolism in tumorigenesis has led to the identification of novel markers for prognostic prediction [11, 12]. Enzymes participating in core metabolic pathways have proven to be essential for the proliferation and survival of cancer cells $[6,7,13,14]$. In this study, we evaluated the relationship of the cancer metabolic enzyme PFKFB4 with the risk of recurrence, metastasis and death in operable breast cancer. We demonstrated that elevated PFKFB4 expression from immunohistochemistry analysis is associated with shorter DFS and OS in breast cancer. Our results established that PFKFB4 is an independent prognostic factor in breast cancer.

Dasgupta et al. found that PFKFB4 can phosphorylate steroid receptor coactivator-3 (SRC3) and lead to increased ER co-activation and cell proliferation. The authors examined 80 samples from the Cancer Genome Atlas and demonstrated that breast cancer patients with high SRC3 and PFKFB4 mRNA expression have unfavorable prognosis [6]. Using public high-throughput expression data, Ros et al. reported that a high level of PFKFB4 mRNA predicted reduced survival in patients with breast cancer and non-small cell lung cancer [15]. PFKFB4 mRNA expression has been proven to be a prognostic marker in non-muscle-invasive bladder cancer [16]. However, quantification of mRNA expression is not easy to perform in routine clinical settings. In this study, we confirmed the prognostic value of PFKFB4 protein in breast cancer using immunochemistry, which can be easily performed in FFPE samples. To the best of our

(See figure on next page.)

Fig. 2 Kaplan-Meier analysis of PFKFB4 in breast cancer. a DFS in all patients $(n=200)$; b OS $(n=200)$; c DFS in luminal subgroup $(n=100)$; $\mathbf{d}$ OS in luminal subgroup ( $n=100)$; e DFS in HER-2-enriched subgroup ( $n=50)$; f OS in HER-2 in HER-2-enriched subgroup $(n=50)$; $g$ DFS in triple-negative subgroup ( $n=50)$; $\mathbf{h}$ OS in triple-negative subgroup ( $n=50$ ). DFS, disease-free survival; OS, overall survival; HER-2, human epidermal growth factor receptor 2. Definitions of subtypes: luminal (ER- and/or PR-positive), HER-2-enriched (ER- and PR-negative, HER-2-positive), and triple-negative (ER-negative, PR-negative, and HER-2-negative) 

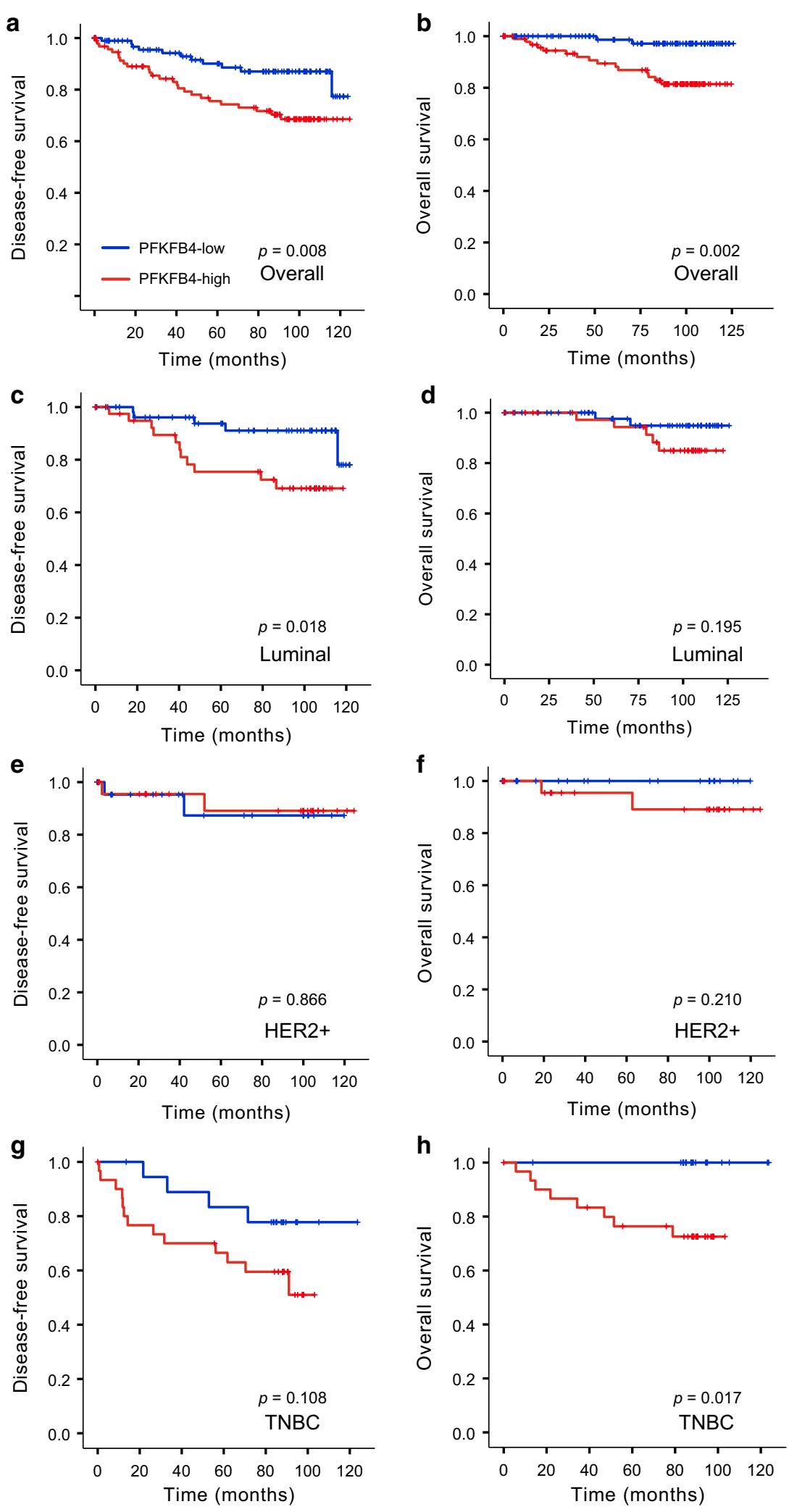
Table 2 Univariate and multivariate analysis of clinicopathological variables and PFKFB4 associated with disease-free survival

\begin{tabular}{|c|c|c|c|c|}
\hline \multirow[t]{2}{*}{ Variable } & \multicolumn{2}{|l|}{ Univariate } & \multicolumn{2}{|l|}{ Multivariate } \\
\hline & $\mathrm{HR}(95 \% \mathrm{Cl})$ & $p$ value & $\mathrm{HR}(95 \% \mathrm{Cl})$ & $p$-value \\
\hline \multicolumn{5}{|l|}{ Age (years) } \\
\hline$\leq 50$ & 1 & - & - & - \\
\hline$>50$ & $1.12(0.58-2.14)$ & 0.734 & - & - \\
\hline \multicolumn{5}{|l|}{ Menopausal status } \\
\hline Premenopausal & 1 & - & - & - \\
\hline $\begin{array}{l}\text { Postmenopau- } \\
\text { sal }\end{array}$ & $1.13(0.58-2.17)$ & 0.726 & - & - \\
\hline \multicolumn{5}{|l|}{ Tumor size (cm) } \\
\hline$\leq 2$ & 1 & - & - & - \\
\hline$>2, \leq 5$ & $1.09(0.56-2.12)$ & 0.800 & - & - \\
\hline$>5$ & $1.00(0.13-7.49)$ & 0.998 & - & - \\
\hline $\begin{array}{l}\text { Cannot be } \\
\text { measured }\end{array}$ & $1.29(0.17-9.69)$ & 0.807 & - & - \\
\hline \multicolumn{5}{|c|}{ Lymph node status } \\
\hline Negative & 1 & - & - & - \\
\hline Positive & $1.46(0.76-2.81)$ & 0.253 & - & - \\
\hline \multicolumn{5}{|l|}{ Grade } \\
\hline Grade 1-2 & 1 & - & - & - \\
\hline Grade 3 & $1.10(0.50-2.43)$ & 0.810 & - & - \\
\hline Unknown & $1.53(0.71-3.29)$ & 0.281 & - & - \\
\hline \multicolumn{5}{|l|}{ ER status } \\
\hline Negative & 1 & - & 1 & - \\
\hline Positive & $0.58(0.29-1.14)$ & 0.112 & $0.51(0.13-2.09)$ & 0.353 \\
\hline \multicolumn{5}{|l|}{ PR status } \\
\hline Negative & 1 & - & - & - \\
\hline Positive & $0.66(0.34-1.30)$ & 0.230 & - & - \\
\hline \multicolumn{5}{|l|}{ HER2 status } \\
\hline Negative & 1 & - & 1 & - \\
\hline Positive & $0.62(0.32-1.22)$ & 0.166 & $1.26(0.44-3.61)$ & 0.671 \\
\hline \multicolumn{5}{|l|}{ Subtype ${ }^{a}$} \\
\hline Luminal & 1 & - & 1 & - \\
\hline HER2-enriched & $0.61(0.20-1.82)$ & 0.373 & $0.26(0.059-1.19)$ & 0.083 \\
\hline Triple-negative & $2.19(1.10-4.35)$ & 0.025 & $1.22(0.24-6.06)$ & 0.812 \\
\hline \multicolumn{5}{|l|}{ PFKFB4 } \\
\hline Negative & 1 & - & 1 & - \\
\hline Positive & $2.52(1.24-5.11)$ & 0.010 & $2.42(1.17-5.00)$ & 0.017 \\
\hline
\end{tabular}

- no data, $C I$ confidence interval, $E R$ estrogen receptor, HER-2 human epidermal growth factor receptor 2, HR hazard ratio, PFKFB4 6-phosphofructo-2-kinase/ fructose-2,6-bisphosphatase 4, $P R$ progesterone receptor

a Definitions of subtypes: luminal (ER- and/or PR-positive), HER-2-enriched (ERand PR-negative, HER-2-positive), and triple-negative (ER-negative, PR-negative, and HER-2-negative)

knowledge, this is the first study supporting the prognostic value of PFKFB4 protein in breast cancer.

PFKFB4 plays an important role in regulating glucose metabolism and directing metabolic pathways required for biosynthesis of macromolecules to maintain cancer cell proliferation [17]. Several groups independently identified PFKFB4 as a key metabolic enzyme in cancer using high-content screening [6-8]. PFKFB4 is required to maintain the balance of glycolytic activity for energy generation and cellular redox in prostate cancer [7]. Using an unbiased RNA interference genome-wide screening assay, Dasgupta et al. discovered PFKFB4 as a dominant modulator of SRC3-dependent cancer cell proliferation [6]. PFKFB4 and SRC-3, an ER co-activator, can hyperactivate ER activity in the presence of estradiol [6], which may explain the correlation between reduced DFS and high PFKFB4 observed in luminal and ER-positive breast cancer. PFKFB4 and SRC-3 are drivers of the growth of basal-subtype breast cancer [6]. This may partially explain the prognostic significance of PFKFB4 in triple-negative and ER-negative subgroups. Further study is needed to determine the expression pattern of PFKFB4 and SRC-3 and the activated status of the PFKFB4-SRC-3 axis in breast cancer. Besides, it is also worthy to note the non-metabolic function of PFKFB4 that are relevant in cancer development. Gao et al. reported that PFKFB4 enhances breast cancer migration by induction of hyaluronan production in a p38-dependent manner [18]. Moreover, PFKFB4 can interact with endothelial tyrosine kinase to modulate chemoresistance of small-cell lung cancer by regulating autophagy [19].

Recent studies reported PFKFB4 as a potential target in cancer. Silencing of PFKFB4 induced apoptosis in p53-deficient cancer cells and inhibited tumor growth [15]. A selective PFKFB4 inhibitor, 5-(n-(8-methoxy4-quinolyl)amino)pentyl nitrate, suppressed the glycolysis process and proliferation in human cancer cell lines rather non-transformed epithelial cells in vitro, suggesting that targeting PFKFB4 may be a promising therapeutic strategy against breast cancer. Our study revealed that almost half $(49.0 \%, 98 / 200)$ of the breast cancer cases in our study had a score 3 (the highest) for PFKFB4 staining, which indicate a large population of breast cancer patients deposit the potential therapeutic target.

This study has some limitations. First, this is a retrospective study, in which we tested the association between PFKFB4 expression with DFS and OS in breast cancer rather than true prediction. Additional study is needed to validate the prognostic value of the novel marker. Second, the number of stage III patients with breast cancer in our cohort was too small $(n=8)$. Thus, the effectiveness of this potential prognostic marker should be applied to this subgroup with caution. Third, even though the study included subjects with all subtypes, the composition of the cohort was not representative of the general patient population in the real world. Larger cohorts are therefore required before PFKFB4 can be recommended for clinical practice. 
Table 3 Univariate and multivariate analysis of clinicopathological variables and PFKFB4 associated with overall survival

\begin{tabular}{|c|c|c|c|c|}
\hline \multirow[t]{2}{*}{ Variable } & \multicolumn{2}{|l|}{ Univariate } & \multicolumn{2}{|l|}{ Multivariate } \\
\hline & $\mathrm{HR}(95 \% \mathrm{Cl})$ & $p$-value & $\mathrm{HR}(95 \% \mathrm{Cl})$ & $p$-value \\
\hline \multicolumn{5}{|l|}{ Age (years) } \\
\hline$\leq 50$ & 1 & - & - & - \\
\hline$>50$ & $1.72(0.66-4.46)$ & 0.266 & - & - \\
\hline \multicolumn{5}{|l|}{ Menopausal status } \\
\hline Premenopausal & 1 & - & - & - \\
\hline $\begin{array}{l}\text { Postmeno- } \\
\text { pausal }\end{array}$ & $1.49(0.58-3.87)$ & 0.411 & - & - \\
\hline \multicolumn{5}{|l|}{ Tumor size (cm) } \\
\hline$\leq 2$ & 1 & - & 1 & - \\
\hline$>2, \leq 5$ & $1.68(0.60-4.71)$ & 0.327 & $2.07(0.69-6.18)$ & 0.193 \\
\hline$>5$ & $3.22(0.39-26.8)$ & 0.279 & $3.43(0.33-36.0)$ & 0.304 \\
\hline $\begin{array}{l}\text { Cannot be } \\
\text { measured }\end{array}$ & $4.21(0.50-35.1)$ & 0.184 & $2.67(0.24-29.7)$ & 0.425 \\
\hline \multicolumn{5}{|l|}{ Lymph node status } \\
\hline Negative & 1 & - & 1 & - \\
\hline Positive & $2.64(0.93-7.49)$ & 0.069 & $3.41(1.08-10.8)$ & 0.037 \\
\hline \multicolumn{5}{|l|}{ Grade } \\
\hline Grade 1-2 & 1 & - & 1 & - \\
\hline Grade 3 & $2.36(0.75-7.45)$ & 0.142 & $2.01(0.59-6.85)$ & 0.264 \\
\hline Unknown & $2.22(0.64-7.65)$ & 0.209 & $2.56(0.64-10.2)$ & 0.183 \\
\hline \multicolumn{5}{|l|}{ ER status } \\
\hline Negative & 1 & - & - & - \\
\hline Positive & $0.64(0.24-1.72)$ & 0.371 & - & - \\
\hline \multicolumn{5}{|l|}{ PR status } \\
\hline Negative & 1 & - & - & - \\
\hline Positive & $0.70(0.26-1.89)$ & 0.477 & - & - \\
\hline \multicolumn{5}{|l|}{ HER2 status } \\
\hline Negative & 1 & - & 1 & - \\
\hline Positive & $0.49(0.17-1.40)$ & 0.184 & $0.67(0.14-3.16)$ & 0.617 \\
\hline \multicolumn{5}{|l|}{ Subtype ${ }^{a}$} \\
\hline Luminal & 1 & - & 1 & - \\
\hline HER2-enriched & $0.71(0.15-3.44)$ & 0.675 & $0.47(0.068-3.21)$ & 0.439 \\
\hline Triple-negative & $2.10(0.76-5.79)$ & 0.152 & $1.13(0.31-4.17)$ & 0.850 \\
\hline \multicolumn{5}{|l|}{ PFKFB4 } \\
\hline Negative & 1 & - & 1 & - \\
\hline Positive & $7.38(1.69-32.3)$ & 0.008 & $7.44(1.67-33.2)$ & 0.009 \\
\hline
\end{tabular}

- no data, $C I$ confidence interval, ER estrogen receptor, HER-2 human epidermal growth factor receptor 2, HR hazard ratio, PFKFB4 6-phosphofructo-2-kinase/ fructose-2,6-bisphosphatase 4, $P R$ progesterone receptor

a Definitions of subtypes: luminal (ER- and/or PR-positive), HER-2-enriched (ERand PR-negative, HER-2-positive), and triple-negative (ER-negative, PR-negative, and HER-2-negative)

\section{Conclusion}

Our study indicates the prognostic value of PFKFB4 protein in breast cancer. High expression of PFKFB4 was associated with reduced DFS and OS in breast cancer. Our findings may therefore promote the further clinical use of PFKFB4 and provides additional prognostic information to oncologists with regard to evaluating risk via assessing cancer metabolic enzymes. Our results, together with previous mechanistic studies, provide a rationale for further clinical investigation to treat cancer by manipulating PFKFB4 expression.

\section{Additional file}

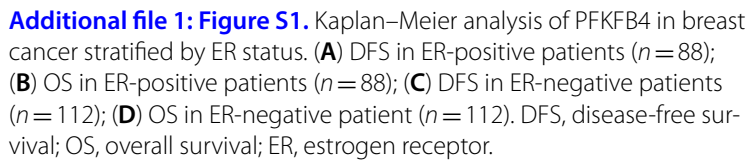

Additional file 1: Figure S1. Kaplan-Meier analysis of PFKFB4 in breast cancer stratified by ER status. (A) DFS in ER-positive patients $(n=88)$; (B) OS in ER-positive patients ( $n=88$ ); (C) DFS in ER-negative patients $(n=112)$; (D) OS in ER-negative patient $(n=112)$. DFS, disease-free survival; OS, overall survival; $E R$, estrogen receptor.

\section{Acknowledgements}

Not applicable.

\section{Authors' contributions}

ZS and XH conceived and designed the study. LY and LW performed the experiments. LY analyzed the data. ZC contributed reagents, materials, and analysis tools. LY and LW wrote the paper. All authors read and approved the final manuscript.

\section{Funding}

This study was supported by grants from the National Natural Science Foundation of China (81202082, 81602316), Shanghai Natural Science Foundation(19ZR1411000), the Ministry of Science and Technology of China (MOST2016YFC0900300, National Key R\&D Program of China). The funders had no role in study design, data collection and analysis, decision to publish, or preparation of the manuscript.

\section{Availability of data and materials \\ Not applicable.}

\section{Ethics approval and consent to participate}

This study was approved by the Ethical Committee of Fudan University ShanghaiCancer Center for Clinical Research (Reference Number: 050432-4-1212B).

The written informed consents were obtained from all the patients.

\section{Consent for publication}

Not applicable.

\section{Competing interests}

The authors declare that they have no competing interests.

\section{Author details \\ ${ }^{1}$ Department of Breast Surgery, Key Laboratory of Breast Cancer in Shanghai, Fudan University Shanghai Cancer Center, Fudan University, 270 Dong-An Rd., Shanghai 200032, People's Republic of China. ${ }^{2}$ Key Laboratory of Breast Can- cer in Shanghai, Fudan University Shanghai Cancer Center, Fudan University, Shanghai, People's Republic of China. ${ }^{3}$ Department of Oncology, Shanghai Medical College, Fudan University, Shanghai, People's Republic of China. \\ ${ }^{4}$ Institutes of Biomedical Sciences, Fudan University, Shanghai, People's Republic of China.}

Received: 15 April 2019 Accepted: 3 June 2019

Published online: 18 June 2019

\section{References}

1. Siegel RL, Miller KD, Jemal A. Cancer statistics, 2018. CA Cancer J Clin. 2018;68:7-30

2. Chen W, Zheng R, Baade PD, Zhang S, Zeng H, Bray F, et al. Cancer statistics in China, 2015. CA Cancer J Clin. 2016;66:115-32. 
3. Curigliano G, Burstein HJ, Winer EP, Gnant M, Dubsky P, Loibl S, et al. Deescalating and escalating treatments for early-stage breast cancer: the St. Gallen international expert consensus conference on the primary therapy of Early Breast Cancer 2017. Ann Oncol. 2017;28:1700-12.

4. Giuliano AE, Connolly JL, Edge SB, Mittendorf EA, Rugo HS, Solin LJ, et al. Breast cancer-major changes in the American joint committee on cancer eighth edition cancer staging manual. CA Cancer J Clin. 2017;67:290-303.

5. Vander Heiden MG, Cantley LC, Thompson CB. Understanding the Warburg effect: the metabolic requirements of cell proliferation. Science. 2009;324:1029-33.

6. Dasgupta S, Rajapakshe K, Zhu B, Nikolai BC, Yi P, Putluri N, et al. Metabolic enzyme PFKFB4 activates transcriptional coactivator SRC-3 to drive breast cancer. Nature. 2018;556:249-54.

7. Ros S, Santos CR, Moco S, Baenke F, Kelly G, Howell M, et al. Functional metabolic screen identifies 6-phosphofructo-2-kinase/fructose-2,6-biphosphatase 4 as an important regulator of prostate cancer cell survival. Cancer Discov. 2012;2:328-43.

8. Goidts V, Bageritz J, Puccio L, Nakata S, Zapatka M, Barbus S, et al. RNAi screening in glioma stem-like cells identifies PFKFB4 as a key molecule important for cancer cell survival. Oncogene. 2012;31:3235-43.

9. Zheng YZ, Cao ZG, Hu X, Shao ZM. The endoplasmic reticulum stress markers GRP78 and CHOP predict disease-free survival and responsiveness to chemotherapy in breast cancer. Breast Cancer Res Treat. 2014;145:349-58.

10. Wang $L$, Yao L, Zheng $Y Z$, Xu Q, Liu XP, Hu X, et al. Expression of autophagy-related proteins ATG5 and FIP200 predicts favorable diseasefree survival in patients with breast cancer. Biochem Biophys Res Commun. 2015:458:816-22.

11. Qiu Y, Cai G, Zhou B, Li D, Zhao A, Xie G, et al. A distinct metabolic signature of human colorectal cancer with prognostic potential. Clin Cancer Res. 2014;20:2136-46.
12. Baek G, Tse YF, Hu Z, Cox D, Buboltz N, McCue P, et al. MCT4 defines a glycolytic subtype of pancreatic cancer with poor prognosis and unique metabolic dependencies. Cell Rep. 2014;9:2233-49.

13. Wang JB, Erickson JW, Fuji R, Ramachandran S, Gao P, Dinavahi R, et al. Targeting mitochondrial glutaminase activity inhibits oncogenic transformation. Cancer Cell. 2010;18:207-19.

14. Christofk HR, Vander Heiden MG, Harris MH, Ramanathan A, Gerszten RE, Wei R, et al. The M2 splice isoform of pyruvate kinase is important for cancer metabolism and tumour growth. Nature. 2008:452:230-3.

15. Ros S, Floter J, Kaymak I, Da Costa C, Houddane A, Dubuis S, et al. 6-Phosphofructo-2-kinase/fructose-2,6-biphosphatase 4 is essential for p53-null cancer cells. Oncogene. 2017;36:3287-99.

16. Yun SJ, Jo SW, Ha YS, Lee OJ, Kim WT, Kim YJ, et al. PFKFB4 as a prognostic marker in non-muscle-invasive bladder cancer. Urol Oncol. 2012;30:893-9.

17. Dang CV. Cancer cell metabolism: there is no ROS for the weary. Cancer Discov. 2012;2:304-7.

18. Gao R, Liu Y, Li D, Xun J, Zhou W, Wang P, et al. PFKFB4 promotes breast cancer metastasis via induction of hyaluronan production in a p38-dependent manner. Cell Physiol Biochem. 2018;50:2108-23.

19. Wang Q, Zeng F, Sun Y, Qiu Q, Zhang J, Huang W, Huang J, Huang X, Guo L. Etk interaction with PFKFB4 modulates chemoresistance of small-cell lung cancer by regulating autophagy. Clin Cancer Res. 2018;24(4):950-62.

\section{Publisher's Note}

Springer Nature remains neutral with regard to jurisdictional claims in published maps and institutional affiliations.
Ready to submit your research? Choose BMC and benefit from:

- fast, convenient online submission

- thorough peer review by experienced researchers in your field

- rapid publication on acceptance

- support for research data, including large and complex data types

- gold Open Access which fosters wider collaboration and increased citations

- maximum visibility for your research: over $100 \mathrm{M}$ website views per year

At BMC, research is always in progress.

Learn more biomedcentral.com/submissions 